Elsevier Editorial System(tm) for Progress in Oceanography

Manuscript Draft

Manuscript Number:

Title: Coastal circulation and hydrography in the Gulf of Tehuantepec, Mexico, during winter

Article Type: Full Length Article

Keywords: Coastal countercurrent; wind-driven currents; buoyancy current; oceanic eddies; hydrography; altimetry

Corresponding Author: Dr Eric D Barton, PhD

Corresponding Author's Institution: Consejo Superior de Investigacion Cientifica

First Author: Eric D Barton

Order of Authors: Eric D Barton; Miguel F Lavin; Armando Trasviña

Abstract: Winter observations of shelf and slope hydrography and currents in the inner Gulf of Tehuantepec are analysed from two field studies in 1989 and 1996 to specify the variability of near-shore conditions under varying wind stress. During the winter period frequent outbursts of 'Norte' winds over the central Gulf result in persistent alongshore inflows along both its eastern and western coasts. Wind-induced variability on time scales of several days strongly influences the shelf currents, but has greater effect on its western coast because of the generation and separation of anticyclonic eddies there. The steadier inflow ( 0.2 m s-1) on the eastern shelf is evident in a strong down-bowing of shallow isosurfaces towards the coast within $100 \mathrm{~km}$ of shore, below a wedge of warmer, fresher and lighter water. This persistent entry of less saline (33.4-34.0), warmer water from the south-east clearly originates in buoyancy input by rivers along the Central American coast, but is augmented by a general shoreward tendency $(0.2 \mathrm{~m} \mathrm{~s}-1)$ in the southeastern Gulf. The resultant shallow tongue of anomalous water is generally swept offshore in the head of the Gulf and mixed away by the strong outflow and vertical overturning of the frequent 'Norte' events but during wind relaxations the warm, low salinity coastal flow may briefly extend further west. In the head of the Gulf, flow is predominantly offshore (<0.2 m s-1) as the alongshore component alternates eastward and westward in association with elevation or depression, respectively, of the pycnocline against the shore. More saline, open ocean water is introduced from the north-western side of the Gulf by the inflow along the west coast. 
During extended wind relaxations, the flow becomes predominantly eastward beyond the shelf while near shore the coastally trapped buoyant inflow from the south-east penetrates across the entire head of the gulf at least as far as its western limit. On the basis of these and other recent observations, it seems that the accepted view of a broad, persistent Costa Rica Coastal Current is the result of averaging over many relatively sparse observations and that the instantaneous $C R C C$ is a highly variable and convoluted flow around and between constantly changing eddies. The buoyancy-driven shelf current reported here forms a hitherto unrecognized, but major, component of this CRCC system. 


\title{
Coastal circulation and hydrography in the Gulf of Tehuantepec, Mexico, during winter
}

5

\author{
1 Instituto de Investigaciones Marinas, Consejo Superior de Investigaciones Científicas, \\ Vigo, SPAIN \\ 2 Departamento de Oceanografía Física, CICESE, Ensenada, Mexico
}

\begin{abstract}
Winter observations of shelf and slope hydrography and currents in the inner Gulf of 15 Tehuantepec are analysed from two field studies in 1989 and 1996 to specify the variability of near-shore conditions under varying wind stress. During the winter period frequent outbursts of 'Norte' winds over the central Gulf result in persistent alongshore inflows along both its eastern and western coasts. Wind-induced variability on time scales of several days strongly influences the shelf currents, but has greater effect on its

20 western coast because of the generation and separation of anticyclonic eddies there. The steadier inflow $\left(\sim 0.2 \mathrm{~m} \mathrm{~s}^{-1}\right)$ on the eastern shelf is evident in a strong down-bowing of shallow isosurfaces towards the coast within $100 \mathrm{~km}$ of shore, below a wedge of warmer, fresher and lighter water. This persistent entry of less saline (33.4-34.0), warmer water from the south-east clearly originates in buoyancy input by rivers along the Central

25 American coast, but is augmented by a general shoreward tendency $\left(0.2 \mathrm{~m} \mathrm{~s}^{-1}\right)$ in the southeastern Gulf. The resultant shallow tongue of anomalous water is generally swept offshore in the head of the Gulf and mixed away by the strong outflow and vertical overturning of the frequent 'Norte' events but during wind relaxations the warm, low salinity coastal flow may briefly extend further west. In the head of the Gulf, flow is

30 predominantly offshore $\left(<0.2 \mathrm{~m} \mathrm{~s}^{-1}\right)$ as the alongshore component alternates eastward and westward in association with elevation or depression, respectively, of the pycnocline against the shore. More saline, open ocean water is introduced from the north-western side of the Gulf by the inflow along the west coast. During extended wind relaxations, the flow becomes predominantly eastward beyond the shelf while near shore the coastally

35 trapped buoyant inflow from the south-east penetrates across the entire head of the gulf at least as far as its western limit. On the basis of these and other recent observations, it seems that the accepted view of a broad, persistent Costa Rica Coastal Current is the result of averaging over many relatively sparse observations and that the instantaneous CRCC is a highly variable and convoluted flow around and between constantly changing

40 eddies. The buoyancy-driven shelf current reported here forms a hitherto unrecognized, but major, component of this CRCC system.
\end{abstract}

Keywords: Coastal countercurrent, wind-driven currents, buoyancy current, oceanic

45 eddies, hydrography, altimetry

Region: Pacific, Central America, Gulf of Tehuantepec 


\section{CONTENTS}

50

1.- INTRODUCTION

2.- THE DATA

55

3.- RESULTS

3.1 Surface hydrography, dynamic height and SST images

3.1.1 Tehuano I

3.1.2 Tehuano II

$60 \quad$ 3.1.3 SST variability from satellite images

3.2 VERTICAL STRUCTURE

3.2.1 T-S diagrams

65 3.2.2 Vertical Sections, January 1989

3.2.2a Eastern shelf

3.2.2b Head of the gulf

3.2.2c Western shelf

$70 \quad$ 3.2.3 Vertical Sections, February 1996

3.3 TIME SERIES TEHUANO I

3.3.1 Variability in wind forcing

3.3.2 Sea Level variability

$75 \quad$ 3.3.3 Currents variability

\section{DISCUSSION AND CONCLUSIONS}

80 5. Acknowledgements

6. References

85 


\section{INTRODUCTION}

In recent decades, considerable effort has been expended in understanding the

90 production of anticyclonic eddies in the Gulf of Tehuantepec (GoT) by intermittent offshore wind jets. The forcing, generation, offshore propagation and general properties of the anticyclones have been well documented and are now reasonably well understood from remote sensing studies (Stumpf, 1975; Legeckis, 1988; Steenburgh et al., 1998; Müller-Karger and Fuentes-Yaco, 2000; Romero-Centeno et al., 2003; González-Silvera

95 et al., 2004; Palacios and Bograd, 2005; Willett, 2006; Trasviña and Barton, 2008). Moreover, modeling studies have highlighted the possible contribution of instability of coastally trapped Kelvin waves to the formation of the anticyclones even in the absence of wind (Zamudio et al., 2006). However, apart from the early large-scale studies of Wyrtki (1965) and Blackburn (1962), and the localized drifter studies of Alvarez et al.

100 (1989), the only in situ measurements reported of the hydrography and currents in the area remain those of the experiment described by Lavín et al. (1992), Barton et al. (1993) and Trasviña et al. (1995; 2003). Like the other studies, those reports concentrated on the spin-up of the anticyclonic eddies and on the dramatic response of the central GoT to wind forcing, but neglected the near-shore circulation, which has a

105 more direct effect on local fisheries and coastal ecology.

The present understanding of the mean and seasonal coastal circulation in the GoT is based on the classical description of the general circulation of the Eastern Tropical Pacific established by Roden (1961) and Wyrtki (1965), and on the more recent

110 geostrophic calculations of Kessler (2006). However, these two descriptions are not completely in agreement. According to the earlier authors, the coastal circulation of the GoT is dominated for a good part of the year by a poleward Costa Rica Coastal Current (CRCC). It is suggested that this current turns offshore at the GoT between November and April, but continues northwestward across it during the rest of the year. Kessler's

115 (2006; his Figures 2 and 7) geostrophic current analysis, on the other hand, indicates that both in the mean and seasonally the CRCC extends only as far as the GoT, where it turns offshore. Both these descriptions have serious limitations; the former is based on ship drift data, while the calculations of Kessler (2006) are based on XBT data averaged into a $1^{\mathrm{o}}$ latitude by $1^{\mathrm{o}}$ longitude mesh. This resolution is inadequate for resolving the coastal 
120 currents, and the data do not include the effect of the salinity on the estimates of the current speed, which was shown to be important in the area by Lavín et al. (2006). The map of surface currents derived from over a thousand drifter tracks (Kessler, 2006: his Figure 4) is blank over the continental margin north of Tehuantepec and has only a few near-shore drifter tracks to the south, which show no defined coastal flow.

125

Furthermore, recent publications describing the geostrophic circulation between the Costa Rica Dome and Central America (Brenes et al., 2008) and the circulation in the GoT from satellite altimetry and surface drifters (Trasviña and Barton, 2008) suggest that the CRCC is hard to detect, partly because of the widespread mesoscale variability. As

130 Kessler (2006) has pointed out, the lack of ocean data off the southwest coast of Mexico is responsible for the inadequate knowledge of the seasonal variability of the CRCC and of the details of the coastal circulation.

In this paper, the structure and several-day variability of the coastal circulation in

135 the Gulf of Tehuantepec are described on the basis of observations carried out during two surveys. The first took place between 9 January and 10 February, 1989 and the second from 10-29 February, 1996. During both, a series of CTD sections around and across the inner Gulf defined the detailed hydrography of the shelf and slope waters. In the 1989 survey, moored and ship-board current observations revealed the horizontal and vertical

140 variation of the flow field in the head of the GoT. With these data, we provide the first detailed information on the nature, extent and variability of the winter-time coastal flows in the GoT and their relation to the Coast Rica Coastal Current.

\section{2. THE DATA}

During Tehuano I, two research vessels, the Mexican El Puma and the U.S. Wecoma, worked together in the Gulf of Tehuantepec between 7 January and 10 February 1989. Four shallow moorings (S1 to S4) monitored flow on the continental shelf of the

150 inner GoT while three deep ( 4000 m) moorings (D1 to D3), with $300 \mathrm{kHz}$ Acoustic Doppler Current Profilers (ADCPs) looking upward from 120 m, were deployed along a line $200 \mathrm{~km}$ offshore and perpendicular to the axis of the wind jet (Figure 1a). 
Some 170 conductivity-temperature-depth (CTD) profiles were obtained over the 155 continental shelf of the Gulf by El Puma while hydrographic sampling was undertaken farther offshore by the Wecoma using both CTD (157 profiles) and SeaSoar (Figure 1a). The latter is a towed undulating vehicle housing a CTD, which allows continuous along track profiling down to $300 \mathrm{~m}$. In effect, this produces a CTD profile every $-2 \mathrm{~km}(1240$ profiles in total) at the optimum towing speed of -8 knots. Cross calibration between the

160 various CTD data sets was carried out to ensure uniformity of data quality (GarcíaCórdoba et al., 1998).

Ship borne ADCP (RDI $150 \mathrm{kHz}$ ) data from Wecoma were ensemble averaged over 3-minute intervals, and manually checked for spurious values. The edited data were 165 merged with a smoothed record of ship's navigation combined from all available sources, including GPS coverage during parts of the day, to provide absolute current profiles every 10 minutes. Profiles typically were acceptable down to $200 \mathrm{~m}$. Instrument and navigational problems after completion of the SeaSoar surveys curtailed ADCP observations to a large extent, although some data are available.

The dynamic topography of the surface is presented here relative to $75 \mathrm{~m}$ with the objective of including stations on the shelf, since we are interested mostly in the coastal circulation. Geostrophic currents were calculated with standard methods for each hydrographic section of all cruises. The reference level was constrained to be relatively 175 shallow at $250 \mathrm{~m}$. However, given the observed weakness of currents below the pycnocline in the zone (Trasviña et al., 1995), the choice seems reasonable. The geostrophic calculations were extended into slope and shelf waters by the method of Reid and Mantyla (1976), which has been shown by Huyer et al. (2005) to produce good agreement in mid-shelf with currents observed by ADCP, with regression slopes close to unit and intercepts near zero.

During the experiment in situ winds at sea were measured on board the research vessels while, on shore, observations were made at 6 or 12 hour intervals at the permanent coastal meteorological stations in Salina Cruz in the head of the Gulf and 
185 Puerto Angel at its western end, as well as at Arriaga, located a short distance inland 150 $\mathrm{km}$ east of Salina Cruz (Figure 1). After eliminating obvious errors, the records were interpolated across short gaps to regular intervals then low pass filtered to eliminate diurnal and other variations with periods less than 40 hours. Sea level observations at the ports of Salina Cruz and Puerto Madero, about $300 \mathrm{~km}$ to the east, were low pass filtered

190 for the study period. Current records from the moorings were edited, averaged over 1 hour intervals and then low pass filtered as above.

During Tehuano II, from 10-27 February 1996, the R/V Altair surveyed the GoT on the sections shown in Figure 1b, which are locally normal to the coast. CTD casts

195 were made to near bottom or to $2000 \mathrm{~m}$, depth permitting. For this cruise period, maps of geostrophic currents were estimated from altimetry data following the method of Strub and James (2002). Gridded maps of sea level anomalies were obtained from from the European Union's ENACT Program (Enhanced ocean data assimilation and climate prediction, http://www.cls.fr/enact), combining data from several altimetry missions. The

200 long-term mean climatology of Levitus and Gelfeld (1992) was used to obtain mean dynamic heights relative to $1000 \mathrm{~m}$ that were added to the anomalies in order to compute geostrophic currents. The maps represent weekly averages and resolve the current field in a horizontal grid of $1 / 3$ of a degree.

205 Satellite Advanced Very High Resolution Radiometer Sea Surface Temperature images for both study periods are $4 \mathrm{~km}$ resolution Pathfinder SST v5 (Product 216) obtained from http://podaac.jpl.nasa.gov/DATA_CATALOG/avhrr.html.

\section{RESULTS}

210

\subsection{Surface hydrography, dynamic height and SST images}

\subsubsection{Tehuano I}

A view of the situation in the GoT in January 1989 is provided by a composite of 215 observations taken over the entire survey (Figure 2). This includes El Puma plus Wecoma CTD and SeaSoar profiles from 8 January to 9 February 1989 and current meter observations between 15 December and 8 February. The hydrographic observations include three repeat surveys of the inner GoT and two repeats of one of the offshore 
transects as well as single occupations of others. Despite the differing record lengths and

220 observation periods of the current observations and the non-synoptic nature of the hydrographic observations, a distinct pattern is evident because of the repetition of the wind events and the oceanic response.

The overall features in Figure 2 are dominated by the $150 \mathrm{~km}$ diameter

225 anticyclonic eddy in the western GoT and by the mixing under the wind jet. The thermal structure and currents associated with these features have been described before (Barton et al., 1992; Trasviña et al., 1995). The warm core of the eddy $\left(26-27^{\circ} \mathrm{C}\right.$, Figure 2a) had relatively uniform salinity $(34.2-34.3$, Figure $2 b)$, while the cool central Gulf $\left(22^{\circ} \mathrm{C}\right)$ had a slightly higher salinity (34.4). These characteristics of the central GoT are caused by 230 mixing beneath the core of the wind jet.

The wind field over the GoT, based on a composite of El Puma observations, is overlaid on Figure 2c. The fanning out of the wind and the anticyclonic curvature to the jet core shows the same characteristic pattern as obtained from the Wecoma data (Barton 235 et al., 1993) and similar to the results of Steerburgh et al. (1998). Puerto Angel at the western end of the gulf lies outside the wind fan, and near-shore winds there had a significant eastward or northeastward (alongshore) component; that is, in opposition to the wind further offshore.

The salinity distribution (Figure $2 b$ ) shows that the freshest (minimum salinity 33.7) surface water occurred in a westward-intruding tongue of low-salinity water along the eastern continental shelf of the GoT. This tongue also had the highest temperature $\left(28^{\circ} \mathrm{C}\right.$, Figure 2a) and the lowest density (21.5, Figure 2c) in this survey. Low salinity and density were also found offshore in the southeastern limit of the sampled area (Figs.

$2452 \mathrm{~b}$ and $2 \mathrm{c}$ ), where the strongest salinity and density fronts were found. There is an overall zonal salinity gradient in Figure 2b, with lower salinity $(<34)$ in the east and higher salinity (>34) in the west.

The low-salinity, high-temperature tongue that seems to extend across the head of 250 the gulf (Figure 2b), apparently pushing westward the coastal low surface temperature 
(Figure 2a), resulted from the impossibility of ship-sampling the lowest temperatures off the central coast of the gulf during wind outbursts, and from a westward shift of the nearshore waters subsequent to events.

The dynamic topography (Figure $2 \mathrm{~d}$ ) is shown for the surface relative to $75 \mathrm{dbar}$.

This relatively shallow reference surface was chosen because there is less variation below this level, and because it allows an extension of the field on to the continental shelf. The anticyclonic eddy in the west dominates the dynamic topography, while a weak cyclonic circulation east of the wind axis is less evident. The flow along the western coast, directed into the gulf, is part of the northern flank of the anticyclonic eddy. The raised dynamic topography along the eastern margin of the gulf indicates an along-shore coastal current in the direction of the inner gulf; this current causes the low-salinity, hightemperature tongue described above. Further to the south, in deeper areas of the eastern GoT, there is a tendency to shore-ward flow feeding into the coastal current.

The composite dynamic topography agrees qualitatively with the mean current vectors observed near $40 \mathrm{~m}$ at the seven moorings (red arrows in Figure 2d). These currents, averaged over the available individual record, are similar to those averaged over the 5-day Tehuano event described by Trasviña et al. (1995). Inflow toward Salina Cruz

270 is evident at S1 and S2 on the western shelf as well as at S4 on the eastern shelf. The flow immediately off Salina Cruz (S3) was directed offshore around the eastern flank of the anticyclone. The two westernmost deep moorings D1 and D2 showed the strongest flows along the periphery of the anticyclone, while D3 in the east showed a strong northeastward onshore flow.

\subsubsection{Tehuano II}

The corresponding map set for the Altair 1996 survey (Figure 3) shows similar 280 structures, but there are some differences. While the maximum temperature was $28{ }^{\circ} \mathrm{C}$ in both cruises, the minimum was lower in Tehuano I $\left(22{ }^{\circ} \mathrm{C}\right.$, Figure $\left.2 \mathrm{a}\right)$ than in Tehuano II $\left(24{ }^{\circ} \mathrm{C}\right.$, Figure $\left.3 \mathrm{a}\right)$. Similarly, while the minimum salinity was 33.7 in both surveys, the maximum was higher in Tehuano I (34.4, Figure 2b) than in Tehuano II (34.3, Figure 3b). 
Since the minimum sea surface temperature and maximum surface salinity occurred in

285 the strongest wind-mixing zone, this suggests that the wind was stronger during Tehuano I, or that the area was sampled sooner after a wind event.

The area of intersection of low SST $\left(25^{\circ} \mathrm{C}\right)$ with the coast was found further west in Tehuano II (Figure 3a) than in Tehuano I (Figure 2a). Accordingly, the tongue of lower salinity $(<34.1)$ over the continental shelf of the eastern GoT penetrated further west across the head of the GoT in 1996 (Figure 3b) than in Tehuano I (Figure 2b). The wind was generally weaker in this survey (compare Figure $3 c$ vs. Figure $2 c$ ), with a confused but generally offshore wind off Salina Cruz, and generally eastward but variable in the other sectors of the gulf.

During this cruise the dynamic topography relative to 75 dbar again indicated anticyclonic circulation on the western side of the GoT with an associated flow into the gulf along the western coast (Figure 3d), although the topography was less steep than in Tehuano I. On the eastern side of the gulf, there was again an onshore flow in the deep area, while a slight rise of dynamic height toward the eastern coast indicated weak coastal flow toward the head of the gulf. Superimposed surface current vectors derived from satellite altimetry are in reasonable agreement with the dynamic topography. The vector field shown is a composite of different weeks selected to coincide closely with CTD station times. The eastern flank of an anticyclonic eddy centred around $13.5^{\circ} \mathrm{N} 97.5 \mathrm{~W}$

305 was visible some $200 \mathrm{~km}$ from shore, only a weak offshore flow was present in the central GoT, and the overall tendency was eastward. In the southeast of the GoT this resulted in onshore flow, probably feeding the near-shore poleward current. The recognized unreliability of altimetry data within $50 \mathrm{~km}$ of the coast precludes any identification of the near-shore flows from the altimetry alone.

\subsubsection{SST variability from satellite images}

The surface distributions described above represent a smoothed and possibly aliased version of the behavior of the surface variables in the GoT in January 1989 and

315 February 1996, since the cruises took around one month to be completed, while satellite images have shown that very important changes can take place in a matter of hours. We 
now show the sequence of events revealed by satellite images. For Tehuano I, the general development during a complete wind event has been described before (Barton et al, 1993; Trasviña et al., 1994), but here we focus on the coastal zone during relaxation.

The sequence of images for 17-21 January during the 1989 experiment in Figure 4 shows a typical occurrence, observed in many other AVHRR scenes. As the wind relaxed, the remnant cold tongue that had originated against the coast under the core of the wind jet shifted westward from the head of the Gulf to be replaced by warmer water

325 from the eastern shelf. Current vectors at $40 \mathrm{~m}$ depth from the shelf moorings and from ship ADCP, overlaid in Figure 4 show a brief reversal of the flow in the head and west of the Gulf associated with the westward displacement of the cool tongue. Initially the offshore flowing cool tongue intersected the coast near the centre of the GoT with warmer coastal inflow from both sides. The furthest westward penetration occurred on

33020 January, on which day the flow at S1 was briefly and weakly westward. One day later another Norte event had started and within hours the cold tongue was re-established in its central position, its temperature had decreased, and inflow from both east and west coasts was re-initiated. These westward intrusions of warm eastern water are clearly associated with the relaxation of the Norte events. On this occasion wind was weakest on 20

335 January, prior to a renewal of Norte conditions. This displacement appears to be evanescent and not associated with any persistent continuation of the flow. The longer wind relaxation of 6-10 January, which produced an almost identical SST sequence, was also accompanied by only a 1 day reversal of flow at S1. However, it should be borne in mind that strong shear occurs in the upper layers, and so surface currents may not be 340 completely represented by the $40 \mathrm{~m}$ observations. The mean flow at $40 \mathrm{~m}$ over 6 weeks on the western shelf was northeastward into the Gulf (Figure 2c), and reversals were brief events among relatively strong variability (see Section 3.3.3, below).

A similar but more extreme relaxation was evident in SST images during the 1996 345 Altair campaign (Figure 5). Prior to the cruise a moderate event had taken place (Figure 5a) but during most of the period 10-27 February winds were generally eastward (Figure $3 \mathrm{c}$ ) and weak. This allowed relaxation at the head of the Gulf and the westward penetration of the fresh, warm coastal waters from the southeast, similar to the 1989 
image sequence. Half way through the cruise (14-15 February, Figure 5b) a brief

resurgence of trans-isthmus winds provoked the reversion to the typical winter cold tongue directly offshore from Salina Cruz, although this was a weak event that allowed Altair to continue working across the central GoT. From then until the end of the cruise on 24 February (Figure 5c and d) the relaxation was again dominant in the inner GoT, with its associated westward extension of the warm inflow from the eastern Gulf. In the

355 final image of the sequence, the warm tongue had extended at least as far as the western limit of the GoT, the furthest observed in our data.

Overlaid on the four SST scenes shown in Figure 5 are geostrophic surface current vectors derived from satellite altimetry. These indicate the persistence of an anticyclonic eddy generated by earlier wind events slowly progressing oceanward in the southwest of the area off the Gulf. The first two scenes show weak offshore flow accompanied the moderate cooling in the central GoT, while the later two indicate eastward drift across the central gulf during wind relaxation. There is some suggestion of cyclonic circulation in the northeastern gulf, but there is no information on the shelf

365 flows because of the unreliability of the near-shore altimetry data. It is clear, however, that any significant coastal flows must be restricted to the inner $50 \mathrm{~km}$.

\subsection{VERTICAL STRUCTURE}

\subsubsection{T-S diagrams.}

The TS distribution in the upper layers in January-February 1989 (Figure 6a) showed characteristic differences across the GoT that reflect the dynamics of the area in

375 relation to the water masses of the eastern Tropical Pacific described by Fiedler and Talley (2006). Close to the eastern coast, the wedge of inflowing water showed up as an extension of the warm surface waters towards salinities of 33.4. These salinities in the temperature range $27.5-29.5^{\circ} \mathrm{C}$ correspond to properties of the Costa Rica Coastal Current waters. In the western Gulf, the effect of evaporation was evident as a slight increase in salinity on the near-surface waters of the anticyclonic eddy. The waters subject to wind mixing in the central GoT were characterized by temperatures $5-7^{\circ}$ lower than the maximum, and by the highest surface salinities (>34.57). Warming after the wind pulses 
was seen by the separation of the central GoT TS curve above the main cluster. The distributions in February-March 1996 (Figure 6b) showed less clear distinctions in the 385 surface waters than in 1989. The central GoT water was warmer and less salty in the 1996 campaign, consistent with weaker winds. Moreover, compared with the 1989 data, salinities were lower in the western anticyclone, and higher in the eastern inflow. In the latter, near surface temperature stratification was evident, also in conformity with a more relaxed wind regime.

In the deeper layers, the TS characteristics during both years (Figure 6) conformed closely to the classification of Emery and Dewar (1982) and Fiedler and Talley (2006). From near surface down to the 26.1 density anomaly, there was a roughly linear decrease of temperature and increase of salinity to the salinity maximum $(\sim 34.83)$

395 at the core of the water mass called Subtropical Subsurface Water by Wyrtki (1967), but which is now considered to be modified $13{ }^{\circ} \mathrm{C}$ Water (13CW, Fiedler and Talley, 2006) brought from the equatorial zone to the eastern tropical Pacific by the Northern Tsuchiya Jet. The low-salinity water above the $13 \mathrm{CW}$ is Tropical Surface Water. Below the $13 \mathrm{CW}$ core, the tendencies reversed toward the influence of Antarctic Intermediate Water near $4006^{\circ} \mathrm{C}$.

\subsubsection{Vertical sections, January 1989}

Hydrographic sections across the continental slope and shelf were made by both vessels at various positions around the GoT between 11 January and 9 February. Those in the eastern gulf were consistent in structure throughout the study, while those in the head and west of the gulf varied significantly.

\subsection{2a Eastern shelf}

The broader eastern shelf was typified by a downward slope of temperature, salinity and density surfaces toward the shore. A zonal section made on 15-16 January (Figure 7) reveals a strong pycnocline above $25 \mathrm{~m}$ offshore that weakened and deepened

415 toward the coast. This was the southernmost section (at $\left.15^{\circ} \mathrm{N}\right)$ in the eastern gulf, but its features were common to others at locations further north on the same coast. The wedge of warmer $\left(>29^{\circ} \mathrm{C}\right)$, less salty $(<33.8)$, lighter water trapped against the coast above the 
pycnocline was reflected in the geostrophic inflow of $>0.2 \mathrm{~m} \mathrm{~s}^{-1}$ to the northwest above $50 \mathrm{~m}$ depth over the shelf. Surface current speeds associated with the fresher inflow

420 ranged between 0.2 and $0.5 \mathrm{~m} \mathrm{~s}^{-1}$ in the various sections. The width of the coastal current was $\sim 110 \mathrm{~km}$.

Almost a month later, a section made northeastward on 6-7 February to intersect the coast near the same location (not shown) showed a similar structure, with surface 425 maximum temperature and minimum salinity almost identical to the earlier section. Again a significant northwestward geostrophic inflow in excess of $0.2 \mathrm{~m} \mathrm{~s}^{-1}$ and $>100 \mathrm{~km}$ wide was indicated in the upper layers over the shelf. Simultaneous ADCP data (Figure 8 top) revealed a northward flow across the entire $150 \mathrm{~km}$ section, strongest in a nearsurface wedge over the slope and shelf, consistent with the calculated geostrophic flow.

430 This section did not extend completely to the coast because of a high density of nighttime artisanal fishing activity.

A section made on $17-18$ January along $15.45^{\circ} \mathrm{N}$ coast-to-coast across the inner gulf (Figure 9) shows the same lower salinity, warm wedge, geostrophic inflow and

435 down-warped isopycnals over the eastern slope. In the centre of the section the depth of the thermocline, halocline and pycnocline showed a strong discontinuity that marks the edge of the anticyclonic eddy. To its east, the isolines domed, while they were depressed to the west, in the northern flank of the anticyclonic eddy. The geostrophic currents indicated anticyclonic flow in the center of the section, with a strong southward outflow

440 from the head of the gulf with surface speeds up to $1 \mathrm{~m} \mathrm{~s}^{-1}$ and a northward inflow of 0.2 $\mathrm{m} \mathrm{s}^{-1}$ immediately to the west. Over the steep western slope, the current had a weak southward component (i.e. in the poleward sense) from the surface to around $150 \mathrm{~m}$. Thus at the start of the relaxation sequence described in 3.1.3, there was evidence of poleward flow near shore in the western GoT while an anticyclonic circulation was 445 present in the centre.

\subsection{2b Head of the Gulf}

In contrast to the stability of conditions on the eastern shelf, the head of the gulf 450 showed strong variability. The three sections shown in Figure 10 were made at roughly 9 
day intervals from the coast near Salina Cruz southward into the central gulf. On all three occasions the isolines between 75 and $200 \mathrm{~m}$ were down-warped towards shore, but those above $75 \mathrm{~m}$ depth were upwelled nearshore on 11-12 January, in an intermediate state on 19-20 January and downwelled on 29 January. In the surface layers, warm, lower salinity 455 water extended offshore into the central gulf, indicating re-circulation offshore of the coastal inflow from the southeast. The geostrophic currents indicated great variability in the flow along the shelf edge in the head of the gulf, associated with the variability of the frontal structures seen in the satellite images. The 11-12 January section, immediately after a brief Norte pulse (Fig 10, indicated strong $\left(>0.8 \mathrm{~m} \mathrm{~s}^{-1}\right.$ ) eastward flow above $50 \mathrm{~m}$

460 over the narrow shelf and slope and equally strong surface flow to the west further offshore. On 19-20 January, during a weakening of the wind, there remained a weak near-shore surface flow to the east against the coast, but over the slope the flow was westward at $>0.2 \mathrm{~m} \mathrm{~s}^{-1}$, coincident with a westward tendency seen at current mooring S3 at $40 \mathrm{~m}$ depth off Salina Cruz (see below, Section 3.2.4) and the relaxation seen in the

465 image sequence of Figure 4. On 29 January, flow over the shelf and slope was predominantly eastward again, though weak $\left(<0.1 \mathrm{~m} \mathrm{~s}^{-1}\right)$. This eastward flow was corroborated by the $\mathrm{S} 3$ record on this date. On the two later dates a narrow band of westward flow extended from the surface to $200 \mathrm{~m}$ just south of $15.5^{\circ} \mathrm{N}$. Of course, currents in the head of the Gulf are extremely variable, with significant cross-shelf 470 component as shown later, and so the geostrophic zonal component provides incomplete information (see Section 3.3.3 and Figure 16 below).

\subsection{2c Western shelf}

As a result of the preceding day's relatively strong wind event, the section at $95.5^{\circ} \mathrm{W}$ on 22 January (Figure 11) showed a surface mixed layer roughly twice as deep $(50 \mathrm{~m})$ as in the previous sections in the head of the Gulf. Just beyond the slope, a nearsurface region of minimal temperature and maximal salinity (>34.3) marked a body of water that clearly originated beneath the core of the wind jet during the event. In its 480 centre, the isolines above the pycnocline were uplifted, some intersecting the surface, while those below it were depressed, an indication of the penetration of vertical overturning beneath the wind jet. Geostrophic flow across this section was eastward over the shelf with a subsurface maximum $>0.6 \mathrm{~m} \mathrm{~s}^{-1}$, but was westward at $>0.2 \mathrm{~m} \mathrm{~s}^{-1}$ south of 
$15.5^{\circ} \mathrm{N}$, coincident with the temperature minimum. This velocity distribution was similar 485 to that observed by an earlier ADCP transect on 16 January (Figure 8, bottom) that showed well organized eastward near-shore flow and westward flow further offshore, during the previous wind outburst. The inward flow nearer shore seems to develop during every wind event and partly to separate from the coast to feed the anticyclone before reaching the inner GoT. The current record at S1, just west of this section, showed 490 peaks of inflow into the GoT around both 16 and 22 January. The westward flow in Figure 11 represents a developing anticyclonic structure, described by Barton et al. (1993), visible in SST images and near-surface ADCP for 22 January.

At the end of the field campaign (February 8-9), three meridional sections over 495 the narrow shelf and slope between 96.0 and $96.75^{\circ} \mathrm{W}$ revealed the replacement of a surface layer of lower salinity water $(<34.0)$ by higher salinity water (34.2-34.4) during the days 8-9 February (Figure 12). This created a subsurface salinity minimum (34.334.1) close to the shelf, while the 28 and $27{ }^{\circ} \mathrm{C}$ isotherms were lifted almost to the surface from their previous horizontal position at $\sim 25 \mathrm{~m}$ depth at the top of the thermocline. The

500 deepening of the isopycnals and the weakening of the pycnocline nearshore over the two days was consistent with a shift in the geostrophic currents from a narrow, weak ( 0.05 $\left.\mathrm{m} \mathrm{s}^{-1}\right)$ nearshore eastward flow to a stronger westward flow $\left(>0.3 \mathrm{~m} \mathrm{~s}^{-1}\right)$. This nearshore poleward current maintained lower salinity in the layers above $75 \mathrm{~m}$ depth near the coast, while an opposed eastward flow offshore introduced the higher salinity from the 505 northwest. Although the sections were spread over about $50 \mathrm{~km}$ along the coast, the changes seem temporal rather than spatial. Strong reversals were seen previously at the nearby mooring S1. This developing eastward flow just offshore toward the inner Gulf was associated with a change from weak northward wind to the strongest Norte event recorded at Salina Cruz during the observation period.

The incomplete ship board ADCP vectors at $16 \mathrm{~m}$ depth from the transects made over the days 6-8 February (not shown) indicated a continuous flow in the poleward sense around the whole coast of the inner GoT at least as far as the first section of Figure 12. The ADCP velocities observed in that section were somewhat stronger than the 515 geostrophic estimates, but showed the same structure with a narrow near-shore flow to 
the east and a broader stronger westward (i.e.poleward) flow just beyond the slope. Even when the major Norte event of 7 February had commenced and a new cold tongue had been generated in the head of the Gulf, the poleward flow persisted at its western limit. The corresponding ship ADCP velocities for the 9 February section showed the same reversal of direction of the flows as indicated by the geostrophic currents with westward flow against the coast and eastward flow further offshore.

\subsubsection{Vertical sections, February 1996}

Three sections from the Altair survey in 1996 demonstrate the repeatability of the winter situation in the Gulf (Figure 13). The western section (left panels) clearly shows the characteristic bowl shaped depression of isolines and strong eastward current associated with the northern periphery of the anticyclonic eddy identified in Figure 5. Flow was eastward right to the coast on this occasion. The easternmost section (right),

530 located close to the Wecoma section of 15-16 January 1989 (cf. Figure 7), shows hydrographic structure and a surface wedge of northwestward flow at up to $0.4 \mathrm{~m} \mathrm{~s}^{-1}$ and $\sim 50 \mathrm{~km}$ width, similar to those seen during Tehuano I. This coastal flow was situated too close to shore to be reliably detected in the altimetry map. A pycnostad was evident in the transition layer in the sections on either side of the Gulf, but not in the central one. Such

535 features were attributed by Trasviña et al. (2003) to subduction of the surface mixed layer waters down isopycnal surfaces in the anticyclonic eddy subsequent to Norte events. The meridional section of 22 February south from Salina Cruz (middle) also was characterized by downwarped isolines against the coast and a continuation of the coastal inflow from the southeast across the head of the GoT at $0.3 \mathrm{~m} \mathrm{~s}^{-1} \mathrm{~cm} / \mathrm{s}$ and $\sim 75 \mathrm{~km}$ wide.

540 Again, the flow was generally too close to shore for detection by altimetry, although there is some indication of westward flow in the head of the Gulf in Figure 5 for the preceding day. The generally eastward wind flow and relaxed conditions in the upper GoT during the Altair campaign seem to have allowed a more extensive westward penetration of the fresher inflow than in 1989.

\subsection{TIME SERIES DURING TEHUANO- I}

\subsubsection{Variability of wind forcing}


Low-passed wind vector series at Arriaga, Salina Cruz and Puerto Angel (Figure 14) show the persistent northerly wind flow through the Chivela Pass into the Pacific. Winds at Puerto Angel, which lies beyond the influence of the Chivela Pass jet, showed a strong eastward component. Winds there are more typical of the coastal region northwest of Punta Cometa $\left(96.25^{\circ} \mathrm{W}\right)$. Arriaga, on the other hand, is close to the jet and so the wind there was similar to Salina Cruz, although diverted slightly southwestward by local topography. At Salina Cruz the wind blows over low terrain and its variation was strongly polarized north-south in the trans-isthmus jet. Persistent episodes of southward wind at Salina Cruz, peaking between 10 and $15 \mathrm{~m} \mathrm{~s}^{-1}$, were separated by brief periods of weak or northward wind. Wind was weaker away from Salina Cruz and more variable in direction. As expected, correlation at zero lag between the meridional components at Salina Cruz and Arriaga was significant (Table 1) at high confidence level, but there was insignificant correlation between Salina Cruz meridional wind with either component at Puerto Angel.

Romero-Centeno et al. (2003) used the surface atmospheric pressure difference between Salina Cruz and Coatzacoalcos (on the Gulf of Mexico coast) as a proxy for the wind observed at La Venta (Figure 1), in the path of the Chivela Pass wind jet. Comparison of the La Venta wind speed, estimated in this way, with the meridional 570 component at Salina Cruz showed significant correlation of 0.75 at zero lag (Figure 15, and Table 1). However, the magnitude of the La Venta wind proxy was greater than that recorded at Salina Cruz. Romero-Centeno et al. (2003) pointed out that the former was based on observations at $28 \mathrm{~m}$ above ground, and therefore stronger than at the $10 \mathrm{~m}$ standard height. Moreover, Salina Cruz is slightly further off the axis of the wind jet than

575 La Venta. The proxy reproduces the variability at Salina Cruz well, although there are a few significant differences, e.g. around 23 Dec 1988 and 12 Jan 1989. In the figure, the proxy has been offset and scaled by the regression coefficients to match the Salina Cruz record.

\subsubsection{Sea Level variability}

Variability on the time scale of 5-10 days in the low-passed sea level (Figure 15a) was significantly greater at Salina Cruz (standard deviation $4.6 \mathrm{~cm}$ ), in the head of the 
GoT, than at Puerto Madero (standard deviation $1.4 \mathrm{~cm})$, on its eastern flank $\left(14^{\circ} 55.2^{\prime} \mathrm{N}\right.$, $\left.58592^{\circ} 22.5^{\prime} \mathrm{W}\right)$. The peak-to-peak oscillations $<10 \mathrm{~cm}$ that dominated the head of the gulf were absent $300 \mathrm{~km}$ to the east, so that the difference series closely resembled the Salina Cruz record. Variability at the two sites was not significantly correlated, and sea level at Puerto Madero was not correlated with the Salina Cruz wind (Table 2). Variability of sea level at Salina Cruz, however, was dominated by the offshore wind jet at zero lag.

590 Correlation between the wind and the series of sea level difference between Salina Cruz and Puerto Madero was slightly higher, again at zero phase difference. Interestingly, the correlation of sea level difference with the La Venta proxy wind was higher still, which suggests the proxy may be a better estimator of the GoT wind variability than the Salina Cruz record. The wind event beginning on 21 January (day 387), which dominated the in

595 situ sampling reported by Lavín et al. (1992), Barton et al. (1993) and Trasviña et al. (1995) was reflected in a drop of sea level at Salina Cruz, modest in both amplitude and duration compared to events both before and after, e.g. 15 December and 8 February.

600

\subsubsection{Current variability}

Shelf currents at $40 \mathrm{~m}$ depth on either side of the GoT were polarized alongshore, while those in the head of the gulf varied widely in direction (Figure 16). The western side (S1) presented more frequent and more energetic fluctuations, alternating in direction, than did the eastern (S4), which was more uni-directional toward the inner

605 Gulf. The western inner gulf mooring (S2) recorded flow generally northeastward toward Salina Cruz, but registered a number of southeastward pulses associated with wind outbursts. The re-installation of this mooring further east, off Salina Cruz (S3), revealed strong, highly variable offshore flows provoked by later wind events.

610 Figure 16c shows the alongshore components of currents at S1 and S4, on opposite sides of the GoT. "Alongshore" is defined in the direction of the principal axes at each site $\left(67^{\circ}\right.$ and $298^{\circ} \mathrm{T}$, respectively) so that positive flows are inward towards Salina Cruz in the head of the Gulf. In the figure, a visual correspondence can be seen between wind pulses and stronger inward flow, although some of the current variability is not

615 directly related to wind. The offshore component of the wind was significantly correlated with the alongshore component of currents at S1, S2 and S4 (Table 3). Use of the La 
Venta wind proxy improved correlations in all cases. However, currents at S3, directly off Salina Cruz, did not yield a significant correlation with wind, most likely because they are strongly governed by the changing meso- and submeso structures in the density

620 field. Alongshore currents on the western side of the GoT were highly correlated between sites $\mathrm{S} 1$ and $\mathrm{S} 2\left(\mathrm{r}^{2}=0.80\right.$, significance $\left.>99.5 \%\right)$, but $\mathrm{S} 3$ and $\mathrm{S} 4$ were correlated neither between themselves nor with S1 and S2. Overall, wind and sea level are correlated at high significance, wind and currents at slightly lower significance, and sea level and currents slightly lower again (Table 4). The generally more significant correlations with

625 the proxy wind suggest that it is more representative of actual wind over the nearshore GoT than the Salina Cruz record.

Currents observed at the three deep sites between 19 January and 4 February (not shown) were described in detail in Barton et al. (1993) and Trasviña et al. (1995). Here

630 we note that at the two western moorings (D1 and D2), currents were consistent with a strong mid-GoT offshore jet in response to the wind event of 21 January and the subsequent development of an anticyclonic eddy that shifted slowly southwestward. In contrast, the flow at D3, the easternmost mooring, was a near constant $30 \mathrm{~cm} \mathrm{~s}^{-1}$ toward the northeast throughout, i.e. supplying an inflow of water toward the shelf on the eastern

635 margin of the GoT. The records shown above are all from $40 \mathrm{~m}$ depth in water depths of $50 \mathrm{~m}$ at $\mathrm{S} 1$ and S4, and $306 \mathrm{~m}$ at $\mathrm{S} 2$ and S3. The mean profiles of current at all sites, including the three deep moorings, indicated that below the pycnocline depth flows were weak. Currents were strongly sheared in the upper layers so that near-surface flows were significantly stronger than those at $40 \mathrm{~m}$.

640

\section{DISCUSSION AND CONCLUSIONS}

The data from our two winter cruises show persistent patterns of hydrography and 645 circulation in the Gulf of Tehuantepec. Two forcing mechanisms seem to be the most relevant at this time of year: the Norte wind-jet events and a buoyancy-driven coastal current. They operate at the same time, but the Nortes are intermittent while the coastal current seems to be steady. Also, their effects are asymmetrical across the Gulf. 
In the western side of the Gulf, the currents are highly variable with frequent reversals in direction. The mean current close to the coast is toward the head of the Gulf, with speed $\sim 0.15 \mathrm{~m} / \mathrm{s}$ in the surface and weakening to near zero below the pycnocline at $50-75 \mathrm{~m}$. The width of this current is $\sim 50 \mathrm{~km}$. The periods of inflowing current are associated with the Nortes and with the near-shore flank of the anticyclonic eddies 655 generated by them. At the start of a Norte event, warm surface water is often seen in satellite images to advance partway toward the head of the gulf before veering offshore to become incorporated into the anticyclonic eddy. As the eddy matures, its northern edge drives the coastal current. The variability of the current time series in this area is correlated with the offshore wind at Salina Cruz. Eddies separate from the coast

660 following wind events, and as they do so, the inward flow on the western side of the GoT relaxes and may reverse briefly.

By contrast, the eastern side of the GoT appears to be subject to a relatively steady coastal inflow from the southeast that is disrupted by the frequent wind jet 665 outbursts near Salina Cruz. The geostrophic current speeds are $\sim 20 \mathrm{~cm} \mathrm{~s}^{-1}$ and the alongshore flow is up to $100 \mathrm{~km}$ wide. The steadiness of this inflow is related to its origin in buoyancy driving by freshwater outflows along the coast of Central America, which do not vary on the rapid time scales of the wind jet. This warm poleward flow carries with it the lowest salinity surface water found anywhere in the gulf, presenting the typical TS characteristics of the CRCC as seen in the early studies. Another factor in the southeastern Gulf, which has been mentioned but not emphasized until now, is the persistent flow towards the coast that must augment the alongshore inflow. Although it appears related to the relatively weak cyclonic re-circulation that counter-balances to an extent the strong anticyclones spun up in the western GoT, it is partly fed (as in 1996)

675 from further west and from the south east. On the basis of our results, in winter the northwestward flow along the coast does not often penetrate completely across the Gulf because of the frequency of the Norte events. However, between events, it can briefly extend across the head of the Gulf to its western flank beyond Salina Cruz, as the northeastward inflow there weakens. This extended poleward flow rarely reaches further west than Puerto Angel. 
Is this pattern of coastal currents consistent with the historical ideas of the circulation scheme along this Eastern Boundary? Wyrtki (1965) and others hypothesized the CRCC as a broad poleward flow along the margin that originates in the Costa Rica

685 Dome, and conveys tropical, low salinity characteristics. However, the flow described by Wyrtki was based on ship-drift data, which may not provide a good description of the true current, especially in a zone of intermittent, strong winds. This supposed poleward current would extend in summer as far as Cabo Corrientes but in winter it would veer offshore at the latitude of the GoT. We find that the buoyant coastal current does not 690 appear to continue beyond $96^{\circ} \mathrm{W}$, and of course the offshore wind and the anticyclonic eddies produce strong offshore currents in the centre of the Gulf.

Kessler (2006) states the CRCC has a mean speed of about $20 \mathrm{~cm} \mathrm{~s}^{-1}$, a transport of more than $5 \mathrm{~Sv}$ and that it extends quite deeply into the water column, with an 695 appreciable flow below the thermocline. The dynamic height charts of 0/400 dbar and 100/400 dbar that support these conclusions are derived from expendable bathythermograph data combined with a climatological salinity profile interpolated onto a $1^{\circ}$ grid, and so detailed structure of the flow is lacking. The only direct observations of the flow with ADCP available here (Figure 8) indeed show peak near-surface speed $>20$

$700 \mathrm{~cm} \mathrm{~s}^{-1}$ with weak northward flow down to at least $200 \mathrm{~m}$. Transport across that incomplete section totals $0.87 \mathrm{~Sv}$, although this does not include the surface and nearshore regions of highest velocity. Estimates from the geostrophic velocity sections provide transports around 0.5 to $0.7 \mathrm{~Sv}$ in the coastal alongshore poleward flow above $200 \mathrm{~m}$. Kessler's (2006) geostrophic calculations were made relative to $400 \mathrm{~m}$, so they

705 do not extend to the shelf and cannot be compared directly with the shallow coastal flow that we have observed. In our hydrographic observations this flow is largely confined to less than $200 \mathrm{~m}$ depth. Most of the ship drift data originally used to support the hypothesis of a CRCC are also located in deeper waters, because shipping routes tend to avoid the rougher conditions on the shelf.

Brenes et al. (2008) reported a poleward flow over the slope that originated between the Costa Rica Dome and the shore, in summer and winter surveys along the central American margin. However this flow, which they identified as the CRCC, was 
tortuous and strongly affected by a variety of eddies, in the Gulf of Fonseca and other

715 zones. Their observations are congruent with Trasviña and Barton's (2008) conclusion on the basis of altimeter and drifter data that the continental margin around Tehuantepec was typified in summer 2000 by an energetic mesoscale eddy regime with no identifiable coherent CRCC. The work of Ballestero and Coen (2004) and Zamudio et al. (2006) also provides evidence of a ubiquitous field of eddies of both signs in the region from

720 Costa Rica north. On balance it seems likely that the smooth, broad CRCC referred to in the "classical" literature reflects the averaging of observations sparse in both time and space and that the instantaneous CRCC is a highly variable and convoluted flow through a time-varying eddy field. However, one component of the flow may be more persistent, namely, the narrow, coastally-trapped buoyancy flow reported here, which is largely

725 restricted to the shelf. Again, this flow is probably spatially intermittent because of the multiple buoyancy sources along the coast and seasonally variable. Such a flow was suspected by Brenes et al. (2008) who suggested there may be an influence of the low salinity from runoff on the flow near the coast during the rainy season.

One feature of Wyrtki's (1965) description of the CRCC that is borne out by the present observations is that the poleward flow does not extend significantly beyond the GoT, where the repeated genesis of anticyclones is seen to divert the coastal flow offshore and prevent its penetration further to the northwest. Kessler (2006) suggested that the CRCC may continue northwest as a subsurface flow, but there is no evidence of 735 this in the present data sets, nor in those of Lavín et al. (2006).

In conclusion, although the detailed hydrographic and current observations during the winters of two years have revealed much of the nature and variability of the nearshore regime in the Gulf of Tehuantepec, much remains to be learned. There is a clear need for in situ data at other times of year. While remote sensing renders valuable information on variability of winds, surface temperature and currents, and near-surface bio-optical properties, it informs only on conditions at or very near the sea surface. Moreover, there are still strong limitations on spatial and temporal resolution and data reliability in the near-shore zones of interest. Questions related to the source and 745 steadiness of the buoyancy driven inflow from the more tropical southeast require 
investigation. In the absence of wind forcing across the Isthmus of Tehuantepec, could this lower salinity flow extend much further north beyond the gulf? Until now, despite the early advances of Clarke (1988) and McCreary et al. (1989), relatively little effort has been made in high resolution modeling of the GoT on scales sufficient not only to

750 incorporate the strong spatial gradients in the wind forcing but also to define the narrow near-shore flows that dominate the GoT response. Again, to validate such model applications, in situ observations in the poorly observed coastal regions will be required. Recent HF radar observations of surface flows in the head of the gulf (R. Durazo, pers. comm.) will provide valuable information on detailed surface circulation in the area

755 directly under the wind jet, but the nature of the water column response in the zone is still unsampled because of the practical difficulty of working during intense events.

Finally, we reiterate that one important component of the Costa Rica Coastal Current system, not previously reported, is the narrow buoyancy flow adjacent to the coast. This current has eluded attention because it lies largely inshore of the early largescale surveys and because it is easily detected neither by altimetry, which is unreliable close to shore, nor by drifters, which tend to separate from shore rapidly. Nevertheless, it appears to influence the sediment distributions in the GoT (Tapia et al., 2007) and its buoyancy input is likely a factor that tends to inhibit the production of cyclones in the eastern GoT. Moreover, it probably plays a pivotal role in the alongshore distribution and nearshore retention of the eggs and larvae of many economically and ecologically significant organisms.

\section{Acknowledgements}

770 Field work was supported by NERC (UK), CONACYT (Mexico), PEMEX (Mexico) and ONR (USA). Exchange visits funded by British Council (UK) and MEC (Spain) facilitated writing up. We acknowledge the invaluable support of the captains, crew and scientific complement of the research vessels El Puma, Wecoma and Altair in difficult circumstances. Technical assistance for the 1989 data by Joaquín García, Víctor Godínez

775 and Carlos Cabrera. Data for 1996 organized by Ana Gabriela Trasviña and Lorian Aviles. 
Alvarez, L. G., Badan-Dangon, A., Valle, A. 1989. On Coastal Currents off Tehuantepec. Estuarine, Coastal and Shelf Science 29,89-96.

785 Ballestero, D., Coen, J.E. 2004. Generation and propagation of anticyclonic rings in the Gulf of Papagayo. International Journal of Remote Sensing, 25, 11,2217-2224.

Barton, E.D., Argote, M.L., Brown, J., Kosro, P.M., Lavin, M., Robles, J.M., Smith, R.L., Trasviña, A., Velez, H.S. 1993. Supersquirt: Dynamics of the Gulf of Tehuantepec, 790 Mexico. Oceanography, 6, 1, 23-30.

Blackburn, M. 1962. An oceanography study of the Gulf of Tehuantepec, U. S. Fish Wildl. Serv. Spec. Sci. Rep. Fish., 404, 28 pp.,

Brenes, C., M.F. Lavín, A. Mascarenhas Jr. 2008. Geostrophic circulation between the Costa Rica Dome and Central America. Deep-Sea Research I, 795 doi:10.1016/j.dsr.2008.02.005, 55(5), 608-629.

García-Córdoba, J., Lavín, M. F. , Robles, J.M. , Argote, M.L. 1998. Datos hidrográficos de la campaña TEHUANOS II: B/O EL Puma, Golfo de Tehuantepec, Enero de 1989. Comunicaciones Académicas, Technical Report CTOFT9808, Serie Oceanografía Física, CICESE, Ensenada, Mexico. 215 pp.

800 Clarke, A. J. 1988. Inertial wind path and sea surface temperature patterns near the Gulf of Tehuantepec and Gulf of Papagayo, J. Geophys. Res., 93(C12), 15,491 - 15,501,.

Emery, W.J., Dewar, L.J. 1982. Mean temperature-salinity, salinity-depth and temperature-depth curves in the North Atlantic and North Pacific. Pergamon Press, 805 Oxford, England, 91 pp.

Fiedler, P. C., Talley, L. D. 2006. Hydrography of the eastern tropical Pacific: a review. Progress in Oceanography, 69, 143-180.

810 González-Silvera, A., Santamaria-del-Angel, E., Millán-Nuñez, R., Manzo-Monroy, H. 2004. Satellite observations of mesoscale eddies in the Gulfs of Tehuantepec and Papagayo (eastern tropical Pacific). Deep-Sea Research II, 51,587-600.

Huyer, A. Fleischbein, J.H., Keister, J., Kosro, P.M., Perlin, N., Smith, R.L., Wheeler, 815 P.A. 2005. Two coastal upwelling domains in the northern California Current system. Journal of Marine Research, 63, 901-929.

Kessler, W.S. 2006. The circulation of the eastern tropical Pacific: a review. Progress in Oceanography 69, 181-217. 
Lavín, M., Robles, J.M., Argote, M.L., Barton, E.D., Smith, R.L., Brown, J., Kosro, P.M., Trasviña, A., Velez Munoz, H.S., Garcia, J. 1992. Física del Golfo de Tehuantepec. Ciencia y Desarrollo, Vol XVIII, 103, 97-108.

825 Lavín, M.F., Beier, E., Gómez-Valdéz, J. Godínez, V.M., García, J. 2006. On the summer poleward coastal current off SW México. Geophysical Research Letters, 33, L02601, doi:10.1029/2005GL024686.

Legeckis, R. 1988. Upwelling off the Gulfs of Panama and Papagayo in the tropical Pacific during March 1985, J. Geophys. Res., 93.

830 Levitus, S., Gelfeld, R. 1992. NODC inventory of physical oceanography profiles. In Key to oceanography records documentation, No. 18. Washington, DC: US Government Printing Office.

McCreary, J., Lee, H., D. Enfield 1989. The response of the coastal ocean to strong offshore winds: with applications to the Gulf of Tehuantepec and Papagayo. J. Mar. Res., $83547,1$.

Müller-Karger, F.E., Fuentes-Yaco, C. 2000. Characteristics of wind-generated rings in the eastern tropical Pacific Ocean. Journal of Geophysical Research, 105,C1, 1271-1284.

Palacios, D.M., Bograd, S.J. 2005. A census of Tehuantepec and Papagayo eddies in the 840 northeastern tropical Pacific. Geophysical Research Letters 32, L23606.

Reid, J. L., Mantyla, A. W. 1976. The effect of the geostrophic flow upon coastal sea elevations in the northern North Pacific ocean. J. Geophys. Res., 81(18), 3100-3110.

Roden, G. I. 1961. On the wind-driven circulation in the Gulf of Tehuantepec and its effect upon surface temperatures, Geofísica Internacional, 1, 55 - 72.

845 Romero-Centeno, R., Zavala-Hidalgo, J., Gallegos, A., O’Brien, J.J. 2003. Isthmus of Tehuantepec wind Climatology and ENSO signal. Journal of Climate, 16, 2628-2639.

Steenburgh, W. J., Schultz, D. M. , Colle, B. A. 1998. The structure and evolution of gap outflow over the Gulf of Tehuantepec, Mexico, Mon. Wea. Rev., 126, 2673-2691.

Strub, P.T., James, C. 2002. The 1997-1998 oceanic El Niño signal along the

850 southeast and northeast Pacific boundaries - an altimetric view. Progress in Oceanography 54, 439-458.

Stumpf, H. G. 1975. Satellite detection of upwelling in the Gulf of Tehuantepec, Mexico, J. Phys. Oceanogr., 5, 383 - 388.

Tapia-Garcia, M, Garcia-Abad, M. C., Carranza-Edwards, A., Vazquez-Gutierrez, F. 855 2007. Environmental characterization of the continental shelf of the Gulf of Tehuantepec, Mexico. Geofísica Internacional, 46, 249-260. 
Trasviña, A, Barton, E.D., Brown, J., Velez, H.S. Kosro, P.M., Smith, R.L. 1995. Offshore wind forcing in the Gulf of Tehuantepec: the asymmetric circulation. Journal of

860 Geophysical Research, 100, 20649-20663.

Trasviña, A., Barton, E.D., Vélez H.S., Brown, J. 2003. Frontal subduction of a cool surface water mass in the Gulf of Tehuantepec, Mexico. Geofísica Internacional, 42,1, pp101-114.

865

Willett, C.S. 1996. A study of anticyclonic eddies in the Eastern tropical Pacific Ocean with integrated satellite, in situ and modeled data. PhD Thesis, University of Colorado, pp127.

870 Wyrtki, K. 1965. Surface currents of the eastern tropical Pacific Ocean. Inter-American Tropical Tuna Commission Bulletin 9, 271-304.

Wyrtki, K. 1967. Circulation and water masses in the eastern equatorial Pacific Ocean. International Journal of Oceanology and Limnology, 1, 2, 117-147.

875 Zamudio, L., Hurlburt, H.E., Metzger, E.J., Morey, S.L., O’Brien, J.J., Tilburg, C., Zavala-Hidalgo, J. 2006. Interannual variability of Tehuantepec eddies. Journal of Geophysical Research 111, C05001. 


\section{List of Figures}

Figure 1 (a) Location map for 1989 survey with topography. CTD/SeaSoar profiles indicated by grey circles, current meter moorings by blue dots, and meteorological sites by red dots. (b) CTD positions for 1996.

Figure 2 For the 1989 Wecoma and Puma surveys, overall composite near-surface (6 m) distributions of (a) temperature (b) salinity (c) density and (d) dynamic height of the sea surface relative to $75 \mathrm{dbar}$. Wind vectors observed from the Puma are overlaid in (c), and mean currents near $40 \mathrm{~m}$ depth at the moorings are overlaid on (d).

Figure 3 For the Altair 1996 survey, overall near-surface $(6 \mathrm{~m})$ distributions of (a) temperature (b) salinity (c) density and (d) dynamic height of the sea surface relative to 75 dbar. Wind vectors observed from the Altair are overlaid in (c), and mean surface currents derived from satellite altimetry are overlaid on (d).

Figure 4 Sea surface temperature images for 17, 20 and 21 January 1989, showing westward displacement of cool tongue between Norte wind pulses. Current vectors from near $40 \mathrm{~m}$ depth at the moorings (blue) and $16 \mathrm{~m}$ from ship ADCP (grey) are shown.

Figure 5 Sea surface temperature images during February 1996 with surface current vectors derived from satellite altimetry overlaid. The dates of the altimetry maps and the closest available temperature image are shown in black and grey, respectively.

Figure 6 TS plots of selected profiles during the (a) 1989 and (b) 1996 campaigns showing more relaxed situation during the later survey.

Figure 7 Sections in the eastern GoT 15-16 January 1989 of (a) temperature, (b) salinity, (c) density and (d) geostrophic velocity relative to 250 dbar. Flow towards the head of the GoT (northwestward) is shaded blue. Section location is indicated by the red line in the map inset.

Figure 8 Sections of absolute ADCP velocity components on (top) 6-7 February 1989 close to the section of Figure 7: (a) northward (b) eastward components along the transect (c) showing $40 \mathrm{~m}$ depth currents vectors; (bottom) 16 January 1989 close to the section of Figure 9: (d) northward (e) eastward components 
along the transect (f) showing $40 \mathrm{~m}$ depth currents vectors. Northward and eastward flows are shaded blue.

Figure 9 Coast-to-coast zonal section across the upper GoT along $15.7^{\circ} \mathrm{N}$ on $17-18$ January 1989: (a) temperature, (b) salinity, (c) density and (d) geostrophic velocity relative to $250 \mathrm{dbar}$. Flow towards the north is shaded blue. Section location is indicated by the red line in the map inset.

Figure 10 Meridional sections along $95^{\circ} \mathrm{W}$ in the head of the Gulf of Tehuantepec of (from top to bottom) temperature, salinity, density and geostrophic velocity relative to $250 \mathrm{dbar}$ on (from left to right) 11-12, 19-20 and 29 January 1989. Flow towards the west is shaded blue. Section location is indicated by the red line in the map inset.

Figure 11 Section in the western GoT of (a) temperature, (b) salinity, (c) density and (d) geostrophic velocity relative to 250 dbar. Flow towards the head of the GoT (northeastward) is shaded blue. Section location is indicated by the red line in the map inset.

Figure 12 Sections at the western limit of the GoT of (from left to right) temperature, salinity, density and geostrophic velocity relative to $250 \mathrm{dbar}$ on (from top to bottom) 8, 8-9 and 9 February. Poleward flow is shaded blue. Section location is indicated by the red line in the map inset.

930 Figure 13 Altair sections in the GoT of (from top to bottom) temperature, salinity, density and geostrophic velocity relative to 250 dbar on (from left to right) 17, 22 and 26 February 1996. Blue shading indicates poleward flow. Section locations are indicated by the red lines labeled L(eft), C(entre) and R(ight) in the map inset.

Figure 14 Vectors of winds, filtered to remove periods $<40$ h, at Salina Cruz, Puerto 935 Angel and Arriaga. The y-axis is oriented northwards. The horizontal bars represent the periods of hydrographic sampling by the two research vessels.

Figure 15 (Top) Variation of low-passed sea level at Puerto Madero and the sea level difference between Salina Cruz and Puerto Madero. (Middle) Low-passed northward component of wind observed at Salina Cruz and the La Venta wind 940 proxy defined by Romero-Centeno et al. (2003). (Bottom) Low-passed components of currents alongshore towards the head of the Gulf of Tehuantepec, rotated into the principal axis of variation at sites $\mathrm{S} 1$ and $\mathrm{S} 4$. 
Figure 16 Low-passed current vectors at shelf moorings S1-S4 (positions in Figure 1). Mooring $S 2$ was recovered and redeployed as $S 3$ further east. The y-axis is 945 oriented alongshore towards the head of the Gulf of Tehuantepec in the direction of the principal axis of variation for S1, S2 and S4. The y-axis represents northward for S3. 
Table 1

950 Salina Cruz northward component of wind vs.

\begin{tabular}{|c|c|c|c|c|}
\hline Winds at & Correlation $\mathbf{r}^{2}$ & $\begin{array}{c}\text { Degrees of } \\
\text { freedom } \mathbf{v}\end{array}$ & $\begin{array}{c}\text { Confidence } \\
\text { Level \% }\end{array}$ & Lag hours \\
\hline Arriaga v & 0.61 & 46 & 99.5 & 0 \\
\hline Puerto Angel u & -0.18 & 86 & - & 0 \\
\hline Puerto Angel v & -0.05 & 79 & - & 0 \\
\hline La Venta proxy & 0.75 & 43 & 99.5 & 0 \\
\hline
\end{tabular}

Table 2

Salina Cruz northward component of wind (La Venta wind proxy) vs.

\begin{tabular}{|c|c|c|c|c|}
\hline Sea level at & Correlation $\mathbf{r}^{2}$ & $\begin{array}{c}\text { Degrees of } \\
\text { freedom v }\end{array}$ & $\begin{array}{c}\text { Confidence } \\
\text { Level \% }\end{array}$ & Lag hours \\
\hline Puerto Madero & -0.28 & 40 & 95 & 0 \\
\hline Salina Cruz & 0.52 & 45 & 99.5 & -6 \\
\hline SC-PM & 0.59 & 44 & 99.5 & -6 \\
SC-PM & 0.77 & 40 & 99.5 & -6 \\
\hline
\end{tabular}

955 Table 3

Salina Cruz northward component of wind (La Venta wind proxy) vs.

\begin{tabular}{|c|c|c|c|c|c|}
\hline Current at & $\begin{array}{c}\text { Correlation } \\
\mathbf{r}^{\mathbf{2}}\end{array}$ & $\begin{array}{c}\text { Degrees of } \\
\text { freedom } \mathbf{v}\end{array}$ & $\begin{array}{c}\text { Confidence } \\
\text { Level \% }\end{array}$ & Lag hours & $\begin{array}{c}\text { Principal } \\
\text { axis } \\
\text { direction }\end{array}$ \\
\hline \multirow{2}{*}{ S1 inward } & -0.23 & 29 & - & 0 & 67 \\
\cline { 2 - 6 } S2 inward & -0.52 & 29 & 99.5 & 6 & \\
\cline { 2 - 6 } & -0.41 & 15 & 95 & 12 & 262 \\
\hline \multirow{2}{*}{ S3 eastward } & -0.66 & 13 & 99.5 & 12 & \\
\cline { 2 - 6 } & 0.16 & 10 & - & 0 & 305 \\
\hline \multirow{2}{*}{ S3 northward } & 0.12 & 10 & - & 0 & 305 \\
\cline { 2 - 6 } & 0.29 & 10 & - & 0 & 298 \\
\hline \multirow{2}{*}{ S4 inward } & -0.49 & 24 & 99.5 & 18 & \\
\cline { 2 - 6 } & -0.48 & 22 & 99 & 24 & \\
\hline
\end{tabular}


Table 4 Sea level difference Salina Cruz-Puerto Madero vs.

\begin{tabular}{|l|l|l|l|l|}
\hline Currents & Correlation $\mathbf{r}^{\mathbf{2}}$ & $\begin{array}{c}\text { Degrees of } \\
\text { freedom v }\end{array}$ & $\begin{array}{c}\text { Confidence } \\
\text { Level \% }\end{array}$ & \multicolumn{1}{|c|}{ Lag hours } \\
\hline S1 inward & -0.36 & 29 & 97.5 & 6 \\
\hline S3 inward & -0.68 & 15 & 99.5 & 0 \\
\hline S4 inward & -0.57 & 21 & 99.5 & 42 \\
\hline
\end{tabular}


Figure 01

Click here to download high resolution image





Click here to download high resolution image















$\begin{array}{llll}-96 & -95.5 & -95 & -94.5\end{array}$


(d) 


\section{Figure 10}

Click here to download high resolution image
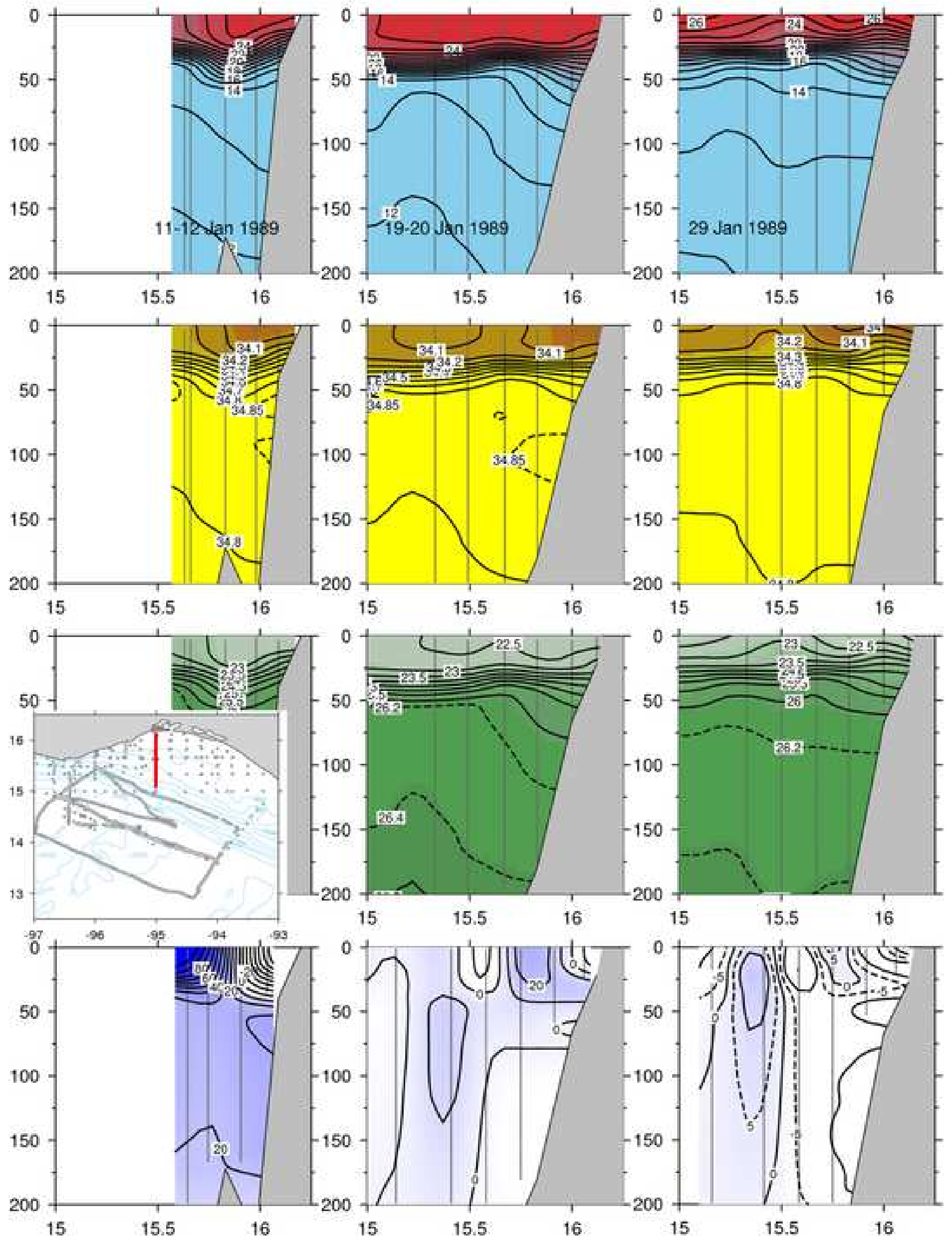

$\begin{array}{lll}15 & 15.5 & 16\end{array}$

15.5

16













\section{Figure 13}

Click here to download high resolution image

Figure 14

Click here to download high resolution image
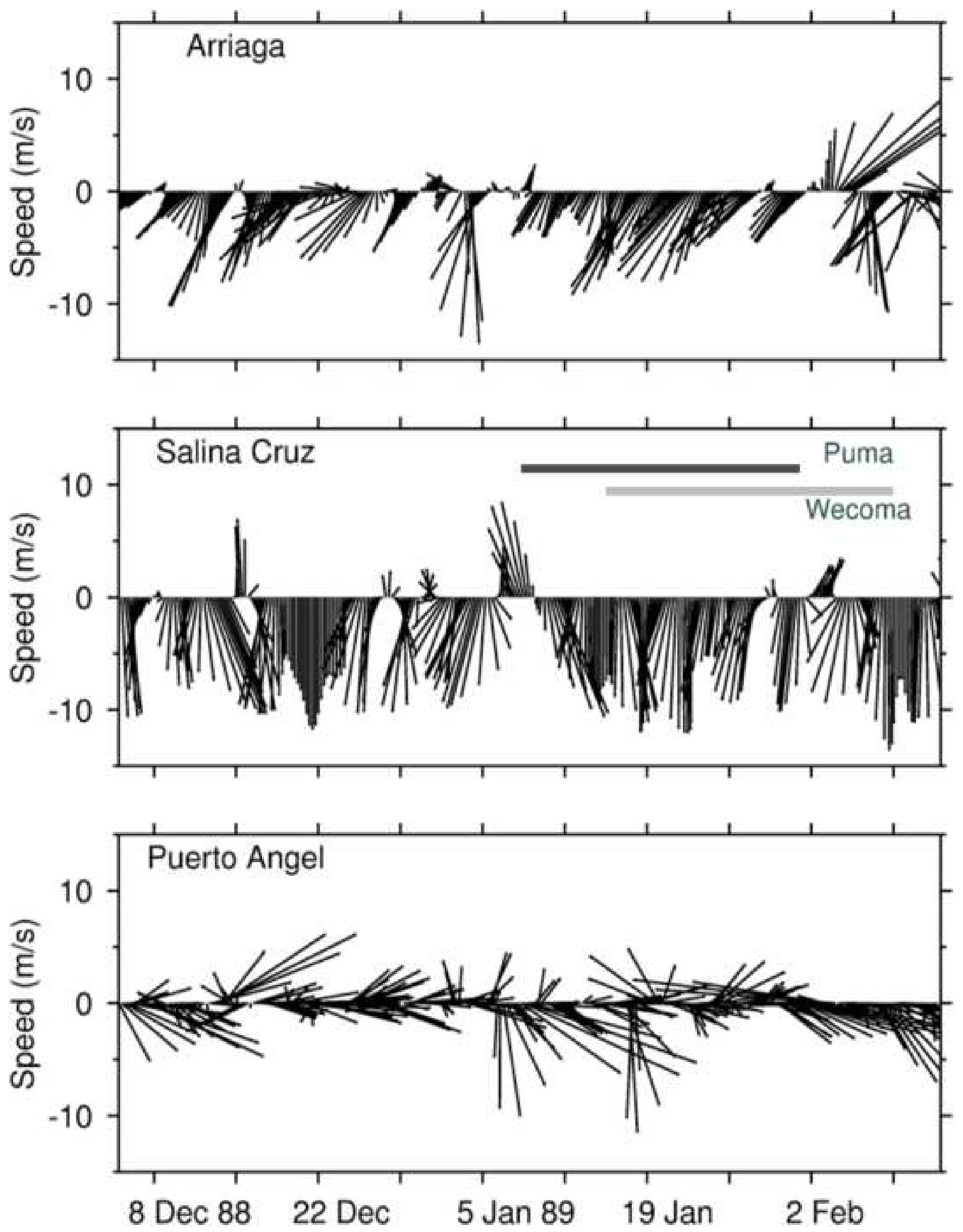



